\title{
Reviewer Acknowledgements for Journal of Education and Training, Vol. 9, No. 1
}

Journal of Education and Training (JET) would like to acknowledge the following reviewers for their assistance with peer review of manuscripts for this issue. Many authors, regardless of whether JET publishes their work, appreciate the helpful feedback provided by the reviewers. Their comments and suggestions were of great help to the authors in improving the quality of their papers. Each of the reviewers listed below returned at least one review for this issue.

\section{Reviewers for Volume 9, Number 1}

A. F. Elgamal, Computer Science Dep.Mansoura University, Egypt

Bryan Spiegelberg, Rider University, United States

Carolyn Stevenson, Kaplan University, United States

John Cowan, Edinburgh Napier University, Scotland

Lazarus Ndiku Makewa, University of Eastern AfricaBaraton, Kenya

Montasser M. A. W. Mahmoud, Imam Abdulrahman bin Faisal Univ., Saudi Arabia

Sofia Freire, Institute of Education of University of Lisbon, Portugal

\section{Dora Wang}

Editorial Assistant

Journal of Education and Training

Macrothink Institute

5348 Vegas Dr.\#825

Las Vegas

Nevada 89108

United States

Phone: 1-702-953-1852 ext.534

E-mail 1: jet@macrothink.org

E-mail 2: jet@macrothink.com

Website: http://jet.macrothink.org 